Original Article

\title{
Anticholinesterase activity of Cinnamomum zeylanicum L. leaf extract
}

\author{
Manoj Kumar Dalai ${ }^{1}$, Santanu Bhadra ${ }^{1}$, Sushil Kumar Chaudhary ${ }^{1}$, Joydeb Chanda ${ }^{1}$, Arun Bandyopadhyay ${ }^{2}$, Pulok K. \\ Mukherjee $^{1, *}$ \\ ${ }^{\text {I} S c h o o l ~ o f ~ N a t u r a l ~ P r o d u c t ~ S t u d i e s, ~ J a d a v p u r ~ U n i v e r s i t y, ~ K o l k a t a ~} 700$ 032, India; ${ }^{2}$ CSIR-Indian Institute of Chemical Biology, \\ Kolkata 700 032, India
}

\begin{abstract}
Cinnamomum zeylanicum (C. zeylanicum) is a tropical evergreen tree of Lauraceae family. It is one of the oldest culinary spices known and used traditionally in many cultures for centuries. In addition to its culinary uses, cinnamon also possesses as a folk remedy of many health disease condition including analgesic, antiseptic, antispasmodic, aphrodisiac, astringent, carminative, haemostatic, insecticidal, and parasiticide and memory enhancing property. This study was aimed to assess the acetylcholinesterase and butyrylcholinesterase inhibitory activity of standardized methanol extract of the C. zeylanicum. Gas chromatography - mass spectrometry (GC-MS) and high performance liquid chromatography (HPLC) analysis were done to identify the presence of eugenol as chemical component and support the neuroprotective activity in the extract. Anticholinesterase inhibitory activity of crude methanol extract of C. zeylanicum leaves and cinnamon oil were evaluated by 96 -well microtiter plate assay and thin layer chromatography bioassay detection methods. This study revealed that cinnamon oil ( $\mathrm{IC}_{50}: 45.88 \pm 1.94$ $\mu \mathrm{g} / \mathrm{ml})$ has better anticholinesterase activity than methanol extract $\left(\mathrm{IC}_{50}: 77.78 \pm 0.03 \mu \mathrm{g} / \mathrm{ml}\right)$. In HPLC analysis, retention time of eugenol in cinnamon oil was found to be $15.81 \mathrm{~min}$ which was comparable with the retention time (15.99 $\mathrm{min})$ of the reference standard, eugenol. Seven chemical compounds were identified by GC-MS analysis, in which eugenol as an important phytoconstituents. Thus the phytochemicals from $C$. zeylanicum methanol leaves extract could be developed as potential source of anticholinesterase activity, with particular benefit in the symptomatic treatment of Alzheimer's disease.
\end{abstract}

Keywords Cinnamomum zeylanicum, anticholinesterase, Alzheimer's disease, eugenol, gas chromatography - mass sepctrometry, high performance liquid chromatography

\section{INTRODUCTION}

Alzheimer's disease (AD) is a progressive and complex neurodegenerative disorder of the brain. Pathophysiology of the disease suggests that deposition of amyloid- $\beta$, accumulation of 1-protein, release of inflammatory mediators and decreasing label of acetylcholine in the cholinergic system could be the possible reason for enhancing neurodegenerative condition of the AD brain (Mukherjee et al., 2007b). It is well known that patients with $\mathrm{AD}$ were deficient of acetylcholine, neuro transmitter that navigates the memory process of central nervous system. This fact has led to develop the cholinergic hypothesis, which focuses impairment of cognitive function in $\mathrm{AD}$ related disorder. The specific events of $\mathrm{AD}$ caused due to termination of the neurologic impulses at cholinergic synapses (White et al., 1977). It escalates to chemist to build a suitable cholinesterase inhibitor as potential model compounds for the treatment of several central nervous system disorders including AD. Synthetic cholinesterase inhibitors such as tacrine, donepezil, rivastigmine and natural origin galantamine have

Correspondence: Pulok K. Mukherjee

E-mail: naturalproductm@gmail.com

Received December 10, 2013; Accepted May 7, 2014; Published

May 31, 2014

doi: http://dx.doi.org/10.5667/tang.2013.0034

(C)2014 by Association of Humanitas Medicine

This is an open access article under the CC BY-NC license.

(http://creativecommons.org/licenses/by-nc/3.0/) been approved for symptomatic treatment for the mild to moderate form of the $\mathrm{AD}$. These inhibitors are primarily nature of competitive or non-competitive type for true acetyl cholinesterase (AChE) and pseudo butyryl cholinesterase (BChE) or for both isoforms. Searching for alternatives, chemical entity of natural origin and its derivatives have been tested scientifically and employed successfully in the treatment of cognitive disorders (Mukherjee and Houghton, 2009; Mukherjee et al., 2007a).

Cinnamomum zeylanicum L. (C. zeylanicum) is the oldest known spice, widely employed in several cultural practices as flavoring, perfumery, beverages and medicines (Mateos-Martín et al., 2012). It grows up to $6-8$ meters height in the wild region. The parts of the plant including rhizomes, fruits/berries, leaves, seeds, barks, flowers, roots, whole plant, gall and bulb are explored for several medicinal properties. Bark of cinnamon is used as antiemetic, antidiarrheal, antiflatulent and general stimulant (Laekeman, 2011). Leaves of the species have showed potent medicinal properties like analgesic, antiseptic, antispasmodic, aphrodisiac, astringent, carminative, homeostatic and insecticidal property (Ranasinghe et al., 2013; Trajano et al., 2010). C. zeylanicum of Iranian origin has been reported for its AChE inhibition activity (Gholamhoseinian et al., 2009). Similarly, fruit of the genus cinnamomum (C. cassia) have also been reported for its potent anticholinesterase activity (Boga et al., 2011). Cinnamon oil possesses hot taste with a spicy odor (O'Shea et al., 2012). Cinnamon oil obtained from leaves and bark has been widely used in food industry for its 


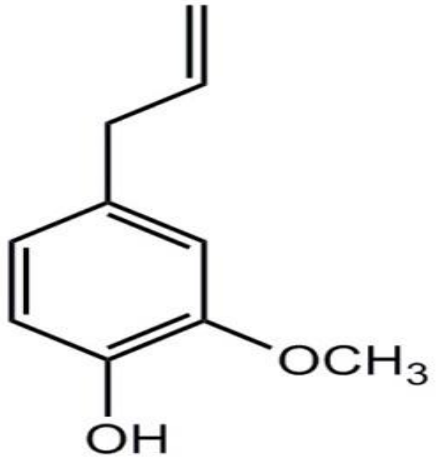

Fig. 1. Chemical structure of eugenol.

antimicrobial property (Mallavarapu et al., 1995). It exhibits wide range of pharmacological activities like antioxidant, antimicrobial, antidiabetic and antihypertensive and vasorelaxant effects (Nyadjeu et al., 2011). Trans-cinnamyl acetate is the major phytoconstituents found in fruits, flowers, and fruit stalks. Eugenol, trans-caryophyllene, linalool, eugenol acetate, benzyl benzoate, $\alpha$-pinene, $\beta$-pinene, $\beta$-caryophyllene, $p$-cymene, camphor and cinnamyl acetate were the most prevalent compound present in oil of $C$. zeylanicum leaves. However, another literature has been reported eugenol and cinnamaldehyde as major chemical constituents of cinnamon oil (Trajano et al., 2010). Eugenol (4-hydroxy-3-methoxy allylbenzene) (Fig. 1), a major phenolic active constituent was reported in oil of cinnamomum species. It possesses antioxidant, antiseptic, carminative, analgesic and neuroprotective activities (Jaganathan and Supriyanto, 2012; Prasad and Muralidhara, 2013). Isoeugenol, an isomer of eugenol, imparts flavor characteristic (Kermasha et al., 1994; Prasad and Muralidhara, 2013). Several spices have been explored for their $\mathrm{AChE} / \mathrm{BChE}$ inhibitory property from our laboratory (Bhadra et al., 2011; Mukherjee et al., 2007a; Satheesh et al., 2009). To continue search of bioactive compounds from spices of Indian origin have led to investigate the cholinesterase inhibition activity of C. zeylanicum, to explore their therapeutic efficacy in neuronal disorder

\section{MATERIALS AND METHODS}

\section{Plant materials}

C. zeylanicum leaves were collected from local market of Kolkata, West Bengal and authenticated as well. A voucher specimen of the plant material (SNPS-1456) has been retained in the herbarium of School of Natural Product Studies, Jadavpur University, Kolkata, India for future reference.

\section{Chemical Reagents}

Acetylthiocholine iodide (ATCI), Butyrylthiocholine iodide (BTCI), Ellman's reagent (5, 5'-dithiobis-(2-nitrobenzoic acid) (DTNB), AChE from bovine erythrocytes, BChE from equine serum, galantamine and standard eugenol was procured from Sigma (Poole, UK). Methanol and all other organic solvents (HPLC reagent grade) were purchased from Merck, India.

\section{Plant extraction}

Shade dried powdered leaves $(120 \mathrm{~g})$ of $C$. zeylanicum were extracted under cold maceration process with methanol $(3 \times$ $600 \mathrm{ml}$ ) for $72 \mathrm{~h}$. This process of extraction was repeated three times. The methanol extract were pooled together and subsequently filtered through a filter paper. The filtrate solvent was evaporated to dryness under reduced pressure using rotary evaporator (EYELA, Tokyo, Japan) at a temperature not exceeding $45^{\circ} \mathrm{C}$. The extract was finally lyophilized and stored under vacuum desiccators for further use. The percentage yield of the extract was $12.6 \%(\mathrm{w} / \mathrm{w})$.

\section{Extraction of cinnamon oil}

To obtain the cinnamon oil from leaves of C. zeylanicum; a hydro distillation process technique was employed. The crushed powder was dissolved in water for $2 \mathrm{~h}$ and then the oil was distilled through a modified Clevenger apparatus for a period of $3 \mathrm{~h}$ (Chaudhary et al., 2013). It afforded a light yellow color of cinnamon oil $(3.4 \%, \mathrm{v} / \mathrm{w})$ was obtained in amber glass container which kept it under refrigeration for future reference.

\section{TLC Bio-autography assay}

In this method, $2.5 \mathrm{~mm}$ silica gel TLC plate $\mathrm{F}_{254}$ (Merck, Darmstadt, Germany) plates were pre-saturated with an appropriate solvent and thoroughly dried just before use. The $C$. zeylanicum methanol extract was placed by using an aliquant of $1 \mathrm{mg} / \mathrm{ml}$ to TLC plate and developed through solvent mixture of toluene/ethyl acetate/formic acid (75:20:0.5). The TLC plate was then sprayed with Ellman's reagent to detect enzyme inhibitory activities in form of developed spots. For detection of enzyme inhibition, TLC plate was spraying with $1 \mathrm{mM}$ ATCI reagent for $\mathrm{AChE}$ inhibition; in case of $\mathrm{BChE}$ inhibition, instead of ATCI, $1 \mathrm{mM}$ BTCI was used. The plate was then sprayed with $3 \mathrm{U} / \mathrm{ml}$ enzyme stock solutions and dried at room temperature for $20 \mathrm{~min}$ again. The plate itself developed a white spots stained within the yellow background, which was immediately recognized. The other TLC plates were used similar way for the TLC bio-autography assay to confirm positive inhibiting activity. To recognize the true inhibitory activity of the extract, white spot appeared at same place in first TLC plate only not in other TLC plate (Bhadra et al., 2012; Satheesh et al., 2009).

\section{6-well microtiter plate method for detection of $\mathrm{AChE}$ and BChE inhibition}

Cholinesterase is the principal enzyme of central nervous system which hydrolyzes the substrate acetylthiocholine/ butyrylthiocholine into prime end product thiocholine which reacts with Ellman's reagent (DTNB) to produce 2nitrobenzoate-5-mercaptothiocholine and 5-thio-2-nitroben zoate which appears as yellow in color and detected at wavelength of $405 \mathrm{~nm}$. AChE/BChE inhibitory activity of methanol extract, cinnamon oil, eugenol and galantamine were studied in 96-well microtiter plate (Bio Rad, 680 XR, USA) method (Bhadra et al., 2011; Ellman et al., 1961). Galantamine was used as the standard cholinesterase inhibitor. $125 \mu \mathrm{l}$ of 3 $\mathrm{mM}$ DTNB, $25 \mu \mathrm{l}$ of $15 \mathrm{mM}$ ATCI (BTCI when measured the

Table 1. $\mathrm{IC}_{50}$ values of the methanol extract, cinnamon oil, eugenol and galantamine against acetylcholinesterase and butyrylcholinesterase

\begin{tabular}{lcc}
\hline Sample & $\begin{array}{c}\text { AChE inhibition IC } \\
\text { value }(\boldsymbol{\mu g} / \mathbf{m l})\end{array}$ & $\begin{array}{c}\text { BChE inhibition IC } \\
\text { value }(\boldsymbol{\mu g} / \mathbf{m l})\end{array}$ \\
\hline $\begin{array}{l}\text { Methanol } \\
\text { extract }\end{array}$ & $77.78 \pm 0.03$ & $88.62 \pm 1.72$ \\
Cinnamon oil & $45.88 \pm 1.94$ & $87.39 \pm 1.60$ \\
Eugenol & $36.42 \pm 1.22$ & $52.14 \pm 1.05$ \\
\hline Galantamine & $22.34 \pm 0.56$ & $25.35 \pm 1.02$ \\
\hline
\end{tabular}

The data were analyzed by one way ANOVA. Values are mean \pm SEM, $n=6$ ( $n=$ Number of replicates) 


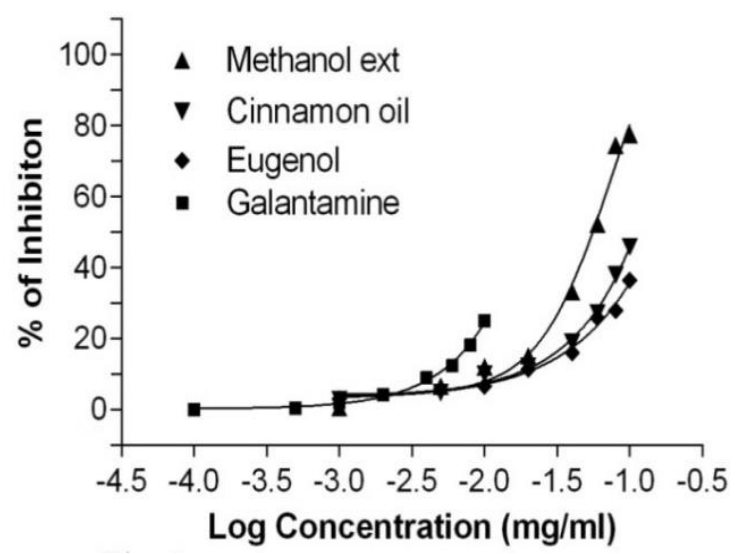

Fig. 2. Dose response curve of methanol extract, cinnamon oil, eugenol and galantamine against aceylcholinesterase.

BChE inhibition), $50 \mu \mathrm{l}$ of buffer and sample was dissolved in phosphate buffer and added in increasing order to each well of 96-well plate and the absorbance was read at $405 \mathrm{~nm}$ every $13 \mathrm{~s}$ for $65 \mathrm{~s}$. $25 \mu \mathrm{l}$ of $0.22 \mathrm{U} / \mathrm{ml}$ of AChE or BChE was added in each well and the absorbance was measured at every $13 \mathrm{~s}$ for 104 s. Each concentration was analyzed for six times. The \% inhibition of the enzyme activity of each test compound concentration was calculated by plotting graph between logarithm of inhibitor concentration in the assay solution and \% enzyme inhibition. The concentration of enzyme inhibitor was expressed as milligram of test substance per milliliter. The linear regression parameters were determined for each curve and the $\mathrm{IC}_{50}$ values of each test compound were calculated by using range of concentration.

\section{Quantification of eugenol in the cinnamon oil by HPLC analysis}

The quantification of eugenol in the cinnamon oil was carried out by Reverse-phase (RP)-HPLC (Shimadzu Prominence, Kyoto, Japan). It is equipped with two Shimadzu LC-20 AD UFLC reciprocating pumps, a variable Shimadzu SPD-M20A Prominence PDA detector and a Rheodyne manual injector with a loop size of $20 \mu \mathrm{l}$. Analytical samples were filtered through $0.45 \mu \mathrm{m}$ ultra membrane filters (Millipore, Germany) before injection. $\mathrm{C}_{18}$ column (Phenomenex-Luna $\mathrm{C}_{18}$, Torrance, CA, USA) $(250 \times 4.6 \mathrm{~nm}, 5 \mu \mathrm{m}$ particle size $)$ was used as stationary phase. Isocratic elution was performed using the mobile phase methanol: $1 \%$ acetic acid in deionized water $(90$ : $10, \mathrm{v} / \mathrm{v}$ ), at a flow rate of $1 \mathrm{ml} / \mathrm{min}$. Detection of the compounds were performed at $254 \mathrm{~nm}$. LC solution software was used to calculate the peak area of standard curve. Identification of standard peak was achieved by comparison of the retention time $\left(\mathrm{R}_{\mathrm{t}}\right)$ of cinnamon oil with standard. The amount of standard eugenol present in the extract was estimated from calibration curve.

\section{Qualitative analysis of eugenol through GC-MS}

The identification and quantification of eugenol present in cinnamon oil was performed by gas chromatography coupled to mass spectrometry (GC/MS - Shimadzu QP Model 5050A) under the following experimental conditions: fused silica capillary column $(30 \mathrm{~m} \times 0.25 \mathrm{~mm}) \mathrm{DB}_{5}$ bonded phase $(0.25$ $\mathrm{mm}$ thick film); Helium as carrier gas at a flow rate of $1.0 \mathrm{ml}$ per min, keeping the temperature was programmed $50^{\circ} \mathrm{C}$ for $1.5 \mathrm{~min}$, followed by an increase of $4^{\circ} \mathrm{C}$ per min up to $200^{\circ} \mathrm{C}$,

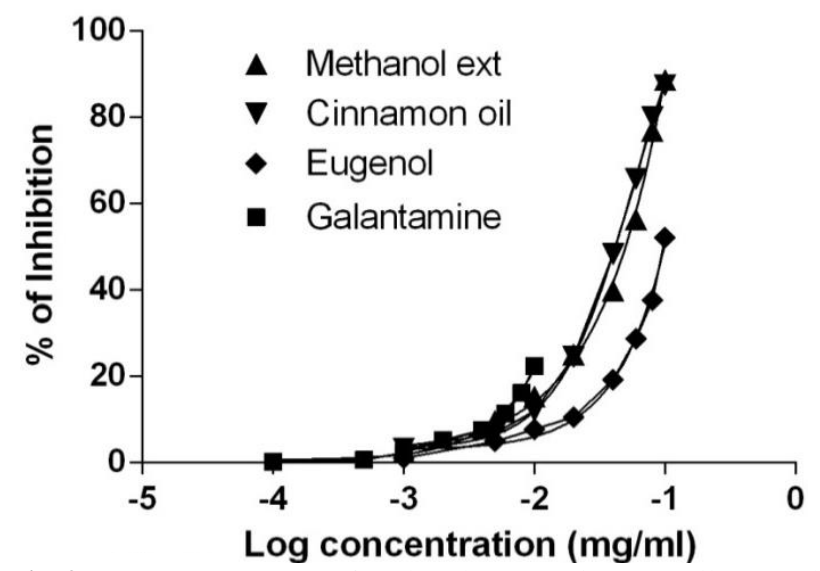

Fig. 3. Dose response curve of methanol extract, cinnamon oil, eugenol and galantamine against butyrylcholinesterase.

then at $10^{\circ} \mathrm{C}$ until reaching $250^{\circ} \mathrm{C}$ were kept constant at this temperature for $5 \mathrm{~min}$; injector temperature: $250^{\circ} \mathrm{C}$ and detector temperature (or interface) $280^{\circ} \mathrm{C}$. Injection volume 0.5 $\mu 1$ was used with split ratio of $1: 25$. Cinnamon oil diluted in methanol at a concentration of $0.1 \mathrm{mg} / \mathrm{ml}$ was used for experimental study. The retention indices of the eugenol were determined with relative value of $n$-alkanes (Kovats, 1965). Peak area of relative compound was measured by comparing Wiley mass spectral data value and in some cases database indices of National Institute of Standards and Technology (Kovats, 1965).

\section{Statistical analysis}

Results of the data were expressed as mean \pm SEM. Dose response curve was performed in graph pad prism software version 4.01 (La Jolla, USA). IC $_{50}$ value of inhibitors was calculated between results of percentage of inhibition versus the concentrations of sample.

\section{RESULTS}

In this work, hydro-distillation process was successfully applied to extract the cinnamon oil from cinnamon leaves. It was transparent, yellow colored with smell of spice. \% yield of the oil was found to be $3.4 \%$ (v/w).

TLC bio-autographic assay was carried out to evaluate the

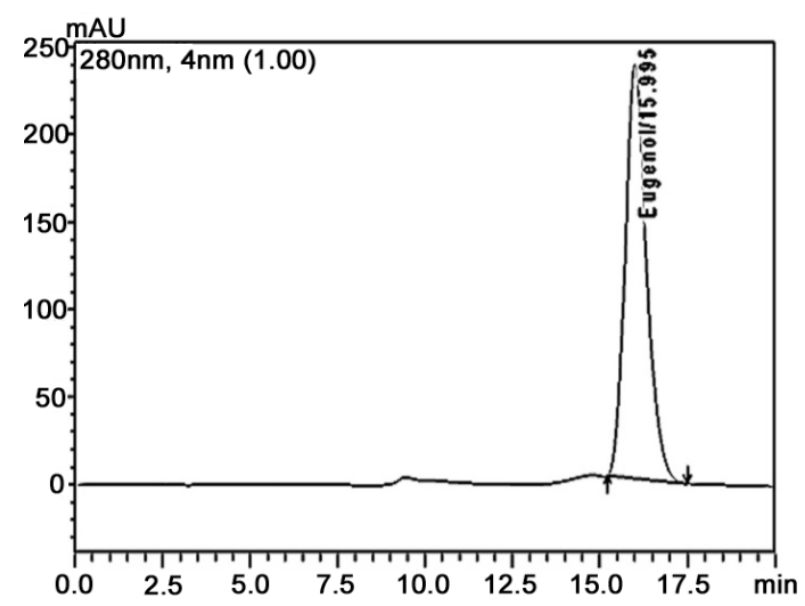

Fig. 4a. HPLC chromatogram of standard eugenol. 


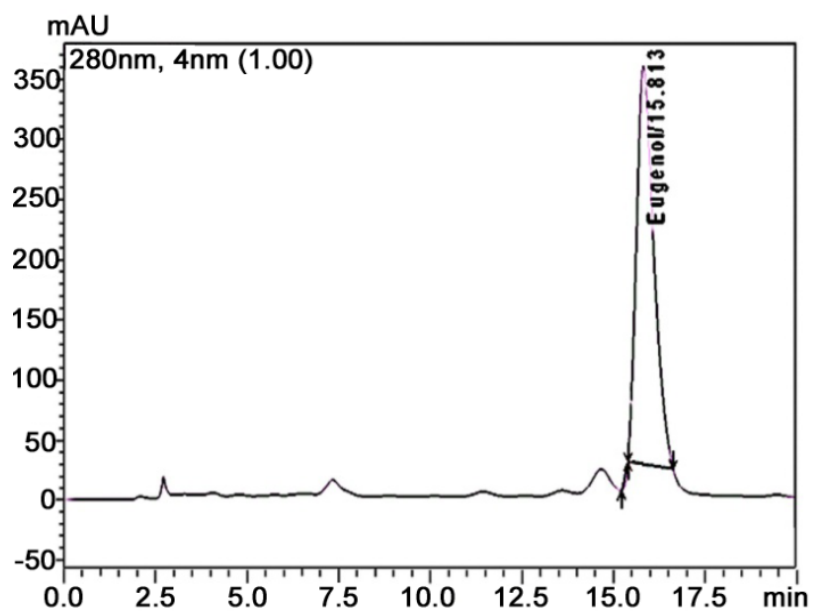

Fig. 4b. HPLC chromatogram of cinnamon oil.

cholinesterase inhibitory activity of standardised plant extract. It was found that methanol extracts of $C$. zeylanicum leaves (1 $\mathrm{mg} / \mathrm{ml}$ ) shows positive inhibitory activity on TLC plate. The result further confirmed with false positive reaction, which does not correspond with positive inhibitory reaction. These positive inhibitory activities indicated number of white spot over yellow background of TLC.

The result of 96-well microtiter plate methods for methanol extract, cinnamon oil, eugenol and standard galantamine has been shown in Table 1. The data value indicates the test and standard chemical compounds have the potential cholinesterase inhibitory activity. Cinnamon oil has shown potent $\mathrm{AChE}$ inhibition with $\mathrm{IC}_{50}$ value of $45.88 \pm 1.94 \mu \mathrm{g} / \mathrm{ml}$ than methanol extract having $\mathrm{IC}_{50}$ value of $77.78 \pm 0.03 \mu \mathrm{g} / \mathrm{ml}$. However, AChE activities of cinnamon oil showed least activity than the standard eugenol compound ( $\mathrm{IC}_{50}: 36.42 \pm 1.22 \mu \mathrm{g} / \mathrm{ml}$ ) used. Moreover, the reference compound galantamine have shown the stronger AChE activity $\left(\mathrm{IC}_{50}: 22.34 \pm 0.56 \mu \mathrm{g} / \mathrm{ml}\right.$ ) than the standard eugenol, cinnamon oil and methanol extract. In contrast to $\mathrm{BChE}$ activity, the cinnamon oil $\left(\mathrm{IC}_{50}: 87.39 \pm 1.60\right.$ $\mu \mathrm{g} / \mathrm{ml})$ have shown the slight potent enzyme activity than the methanol extract $\left(\mathrm{IC}_{50}: 88.62 \pm 1.72 \mu \mathrm{g} / \mathrm{ml}\right)$ of $C$. zeylanicum.
Table 2. GC-MS analysis of cinnamon oil

\begin{tabular}{lcc}
\hline Chemical constituents & Retention time & Area in \% \\
\hline Camphene & 26.29 & 1.02 \\
Eugenol & 27.98 & 22.91 \\
Cinnamaldehyde & 29.23 & 66.74 \\
Tetratetracontane & 51.42 & 0.73 \\
Penta tri acontane & 53.36 & 1.12 \\
Heptacosane & 55.23 & 2.10 \\
Triacontane & 57.35 & 3.30 \\
\hline \multicolumn{1}{c}{ Total components of oil } \\
\hline
\end{tabular}

Similarly, the standard biomarker compound eugenol have shown potent $\mathrm{BChE}$ activity with $\mathrm{IC}_{50}$ value of $52.14 \pm 1.05$ $\mu \mathrm{g} / \mathrm{ml}$ and found to be active than the cinnamon oil and methanol extract. The reference compound galantamine have shown $\mathrm{IC}_{50}$ value $25.35 \pm 1.02 \mu \mathrm{g} / \mathrm{ml}$ and possess as most active against BChE. Data value (Table 1) was also determining the cholinesterase enzyme affinity of the studied substances towards more AChE than BChE. Dose response curve (Figs. 23 ) of the methanol extract, cinnamon oil, eugenol and galantamine was shown in increase in percentage of $\mathrm{AChE}$ and $\mathrm{BChE}$ inhibition with increase in concentration of test samples. The cinnamon oil from $C$. zeylanicum has exhibited potent $\mathrm{AChE}$ and $\mathrm{BChE}$ inhibition over other test compounds.

RP-HPLC method was carried out to know the purity of natural product extract (Ross, 1976). The complex mixture of the chemical compound in natural product was separated on the basis of the affinity towards stationary phase and mobile phase gradient. The label of eugenol in cinnamon oil was calculated from linear regression equation $(\mathrm{y}=1.519065 \mathrm{e}+007 \mathrm{X}+$ 1659936). The following equation showed a good agreement between peak area and used concentration $(0.1-1.0 \mu \mathrm{g} / \mathrm{ml})$

RT: $5.50-60.00$ SM: $15 G$

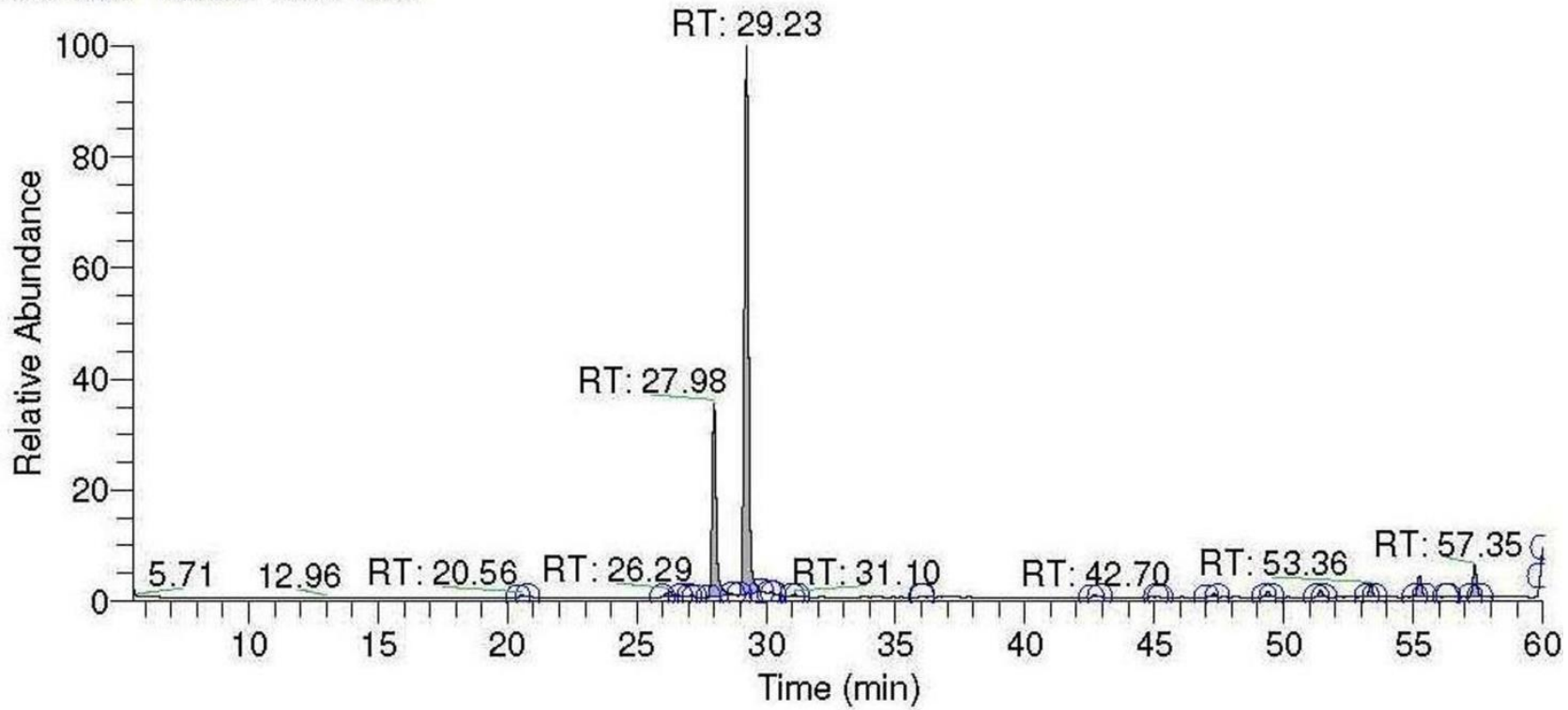

Fig. 5. GC-MS chromatogram of cinnamon oil. 
with a correlation coefficient, $r^{2}=0.984$. The identity of eugenol in cinnamon oil was affirmed by comparing the retention times of reference compound. Chromatogram of HPLC analysis showed retention time of eugenol in cinnamon oil was $15.81 \mathrm{~min}$ (Fig. 4a and b). The percentage content of eugenol in cinnamon oil was found to be $0.205 \mathrm{mg}$ per $\mathrm{ml}$.

In GC-MS analysis, seven chemical compounds were identified in cinnamon oil which comprising of $97.92 \%$ of the total cinnamon oil. Cinnamaldehyde $(66.74 \%)$ and eugenol $(22.91 \%)$ were found main components of cinnamon oil, followed by Triacontane $(3.30 \%)$, Heptacosane $(2.10 \%)$, Penta tri acontane $(1.12 \%)$, Camphene $(1.02 \%)$ and Tetratetracontane $(0.73 \%)$ were other minor constituents (Table 2, Fig. 5).

\section{DISCUSSION}

C. zeylanicum oil of different region contains eugenol as major chemical constituent and found abundant amount in Lauraceae family (Rana et al., 2012). It has been reported that eugenol containing spices able to restore the normal behavior of an experimental animal against acrylamide induced oxidative stress (Prasad and Muralidhara, 2013). Thus, it prompted to investigate the standardized extract of $C$. zeylanicum leaves and its essential oil for anticholinergic activity.

The result of TLC bio-autographic/96-well microtiter plates confirmed the cinnamon leaves and oil has potential anticholinesterase activity. Cholinesterase inhibitors obtained from plant sources have been extensively studied for neurodegenerative disorder. These natural occurring compounds have provided convincing evidence of anticholinesterase activity in mild to moderate form of Alzheimer's disease (Yang et al., 2003). It has been hypothesized that both $\mathrm{AChE} / \mathrm{BChE}$ play critical role in maintaining chemical neurotransmitter $(\mathrm{ACh})$ in the region of human brain. However, the ratio $\mathrm{AChE} / \mathrm{BChE}$ label in certain region of brain is altered in due course of AD. These changes provide strong evidence of decline in label of acetylcholine in the region of dementia brain (Bhadra et al., 2012). This needs to design a suitable chemical substance which can optimize the therapeutic balance between $\mathrm{AChE}$ as well as BChE inhibition. The tested substances were shown more affinity towards AChE than BChE. This may be due to presence of chemical substance eugenol as constituent in methanol extract (Laekeman, 2011) and cinnamon oil. The incurred data clearly demonstrate the active principle contain tested substance have the potential cholinesterase activity and support the earlier evidence of claiming eugenol contain plant extract has possible anticholinesterase activity (Kumar et al., 2009).

The content of eugenol in cinnamon oil was standardized with RP-HPLC and identified through gas chromatography-mass spectrometry (GC-MS) technique. GC-MS technique is widely employed for identification and quantification of volatile compound present in essential oil (Bhadra et al., 2012). The variation of the different chemical compounds identified in cinnamon oil may be due to geographical location or soil condition (Rana et al., 2012). The identification of chemical compounds in cinnamon oil was corelated with data value of retention indices and mass spectra obtained from data library (Adams, 2001).

The present study highlights the eugenol as important constituent of $C$. zeylanicum leaf oil. Further, the studied plant has well characterised as potent cholinesterase inhibitory activity. Therefore, the underlying active principles of $C$. zeylanicum may have therapeutic value in treatment of neurodegenerative disease such as $\mathrm{AD}$.

\section{ACKNOWLEDGEMENTS}

Thanks are due to the All India Council for Technical Education (AICTE), New Delhi for providing QIP research scholarship to the first author.

\section{CONFLICT OF INTEREST}

The authors declare that there is no conflict of interest.

\section{REFERENCES}

Adams RP. Identification of Essential Oils by Ion Trap Mass Spectroscopy. (San Diego, USA: Academic Press), 2001.

Bhadra S, Mukherjee PK, Bandyopadhyay A. Cholinesterase inhibition activity of Marsilea quadrifolia Linn. an edible leafy vegetable from West Bengal, India. Nat Prod Res. 2012;26:1519-1522.

Bhadra S, Mukherjee PK, Kumar NS, Bandyopadhyay A. Anticholinesterase activity of standardized extract of Illicium verum Hook.f. fruits. Fitoterapia. 2011;82:342-346.

Boğa M, Hacıbekiroğlu I, Kolak U. Antioxidant and anticholinesterase activities of eleven edible plants. Pharm Biol. 2011;49:290-295.

Chaudhary SK, Maity N, Nema NK, Bhadra S, Saha BP, Mukherjee PK. Angiotensin converting enzyme inhibition activity of fennel and coriander oils from India. Nat Prod Comm. 2013;8:671-672.

Ellman GL, Lourtney DK, Andres V, Gmelin G. A new and rapid colorimetric determination of acetylcholinesterase activity. Biochem Pharm.1961;7:88-95.

Gholamhoseinian A, Moradi MN, Sharifi-far F. Screening the methanol extracts of some Iranian plants for acetylcholinesterase inhibitory activity. Res Pharm Sci. 2009;4:105-112.

Jaganathan SK, Supriyanto E. Antiproliferative and molecular mechanism of eugenol-induced apoptosis in cancer cells. Molecules. 2012;17:6290-6304.

Kermasha S, Goetghebeur M, Dumont J. Separation and Characterization of Pepper-Contaminated cinnamon Using HPLC Analyses. J Food Sci Tech. 1994;27:578-582.

Kovats E. Gas chromatographic characterization of organic substances in the retention index system. (New York, USA: Marcel Dekker), 1965.

Kumar NS, Mukherjee PK, Bhadra S, Saha BP, Pal BC. Acetylcholinesterase inhibitory potential of a carbazole alkaloid, Mahanimbine from Murraya koenigii. Phytother Res. 2010;24:629-631.

Kumar P, Singh VK, Singh DK. Kinetics of enzyme inhibition by active molluscicidal agents ferulic acid, umbelliferone, eugenol and limonene in the nervous tissue of snail Lymnaea acuminate. Phytother Res. 2009;23:172-177. 
Laekeman G. Assessment report on Cinnamomum verum J. S. Presl, cortex and corticisaetheroleum. (London, UK: European Medicines Agency), 2011.

Mallavarapu GR, Ramesh S, Chandrasekhara RS, Rajeswara Rao BR, Kaul PN, Bhattacharya AK. Investigation of the essential oil of cinnamon leaf grown at Bangalore and Hyderabad. Flavour Frag J. 1995;10:239-242.

Mateos-Martín ML, Pérez-Jiménez J, Fuguet E, Torres JL. Profile of urinary and fecal proanthocyanidin metabolites from common cinnamon (Cinnamomum zeylanicum L.) in rats. Mol Nutr Food Res. 2012;56:671-675.

Mukherjee PK, Ahamed KF, Kumar V, Mukherjee K, Houghton PJ. Protective effect of biflavones from Araucaria bidwillii Hook in rat cerebral ischemia/reperfusion induced oxidative stress. Behav Brain Res. 2007b;178:221-228.

Mukherjee PK, Houghton PJ. The worldwide phenomenon of increased use of herbal products: Opportunities and threats. In Evaluation of Herbal Medicinal Products, Mukherjee PK, Houghton PJ ed. (London, UK: Pharmaceutical Press), pp. 3-12, 2009.

Mukherjee PK, Kumar V, Houghton PJ. Screening of Indian medicinal plants for acetylcholinesterase inhibitory activity. Phytother Res. 2007a;21:1142-1145.

Nyadjeu P, Dongmo A, Nguelefack TB, Kamanyi A. Antihypertensive and vasorelaxant effects of Cinnamomum zeylanicum stem bark aqueous extract in rats. J Complement Integr Med. 2011;8.

O'Shea SK, Von Riesen DD, Rossi LL. Isolation and analysis of essential oils from spices. J Chem Educ. 2012;89:665-668.
Prasad SN, Muralidhara. Neuroprotective Efficacy of Eugenol and Isoeugenol in Acrylamide-Induced Neuropathy in rats: Behavioral and Biochemical evidence. Neurochem Res. 2013;38:330-345.

Rana VS, Langoljam RD, Verdeguer M, Blázquez MA. Chemical variability in the essential oil of Cinnamomum tamala L. Leaves from India. Nat Prod Res. 2012;26:13551357.

Ranasinghe P, Pigera, S, Premakumara GAS, Galappaththy P, Constantine GR, Katulanda P. Medicinal properties of 'true' cinnamon (Cinnamomum zeylanicum): a systematic review. BMC Complement Altern Med. 2013;13:275-284.

Ross MSF. Analysis of cinnamon oils by high-pressure liquid chromatography. J Chromatogr. 1976:118:273-275.

Trajano VN, Lima EO, Travassos AE, de Souza EL. Inhibitory effect of the essential oil from Cinnamomum zeylanicum Blume leaves on some food-related bacteria. Food Sci Tech. 2010;30:771-775.

White P, Hiley CR, Goodhardt MJ, Carrasco LH, Keet JP, Williams IE, Bowen DM. Neocortical cholinergic neurons in elderly people. Lancet. 1977;309:668-671.

Yang CY, Lv ZP, Zheng CG. Efficacy and reliability of huperzine A in mild and moderate Alzheimer's disease. Chin J Clin Rehabil. 2003;7:4258-4259. 